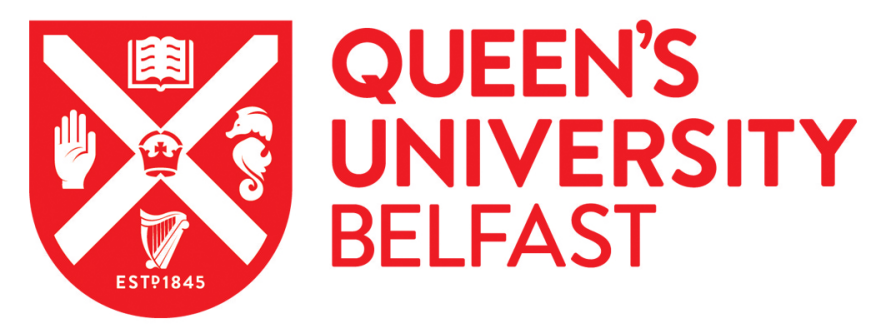

\title{
The global diversity and distribution of lizard clutch sizes
}

Meiri, S., Avila, L., Bauer, A., Chapple, D., Das, I., Doan, T., Doughty, P., Ellis, R., Grismer, L., Kraus, F., Morando, M., Oliver, P., Pincheira-Donoso, D., Ribeiro-Junior, M., Shea, G., Torres-Carvajal, O., Slavenko, A., \& Roll, U. (2020). The global diversity and distribution of lizard clutch sizes. Global Ecology \& Biogeography. https://doi.org/10.1111/geb.13124

Published in:

Global Ecology \& Biogeography

Document Version:

Peer reviewed version

Queen's University Belfast - Research Portal:

Link to publication record in Queen's University Belfast Research Portal

Publisher rights

Copyright 2020 Wiley. This work is made available online in accordance with the publisher's policies. Please refer to any applicable terms of use of the publisher.

\section{General rights}

Copyright for the publications made accessible via the Queen's University Belfast Research Portal is retained by the author(s) and / or other copyright owners and it is a condition of accessing these publications that users recognise and abide by the legal requirements associated with these rights.

Take down policy

The Research Portal is Queen's institutional repository that provides access to Queen's research output. Every effort has been made to ensure that content in the Research Portal does not infringe any person's rights, or applicable UK laws. If you discover content in the Research Portal that you believe breaches copyright or violates any law, please contact openaccess@qub.ac.uk. 


\title{
The global diversity and distribution of lizard clutch sizes
}

\author{
Shai Meiri, Luciano Avila, Aaron M. Bauer, David G. Chapple, Indraneil Das, Tiffany M. Doan, Paul \\ Doughty, Ryan Ellis, Lee Grismer, Fred Kraus, Mariana Morando, Paul Oliver, Daniel Pincheira- \\ Donoso, Marco Antonio Ribeiro-Junior, Glenn Shea, Omar Torres-Carvajal, Uri Roll, Alex Slavenko
}

1School of Zoology \& Steinhardt Museum of Natural History, Tel Aviv University, Tel Aviv, Israel

2Instituto Patagónico para el Estudio de los Ecosistemas Continentales, Puerto Madryn, Chubut, Argentina

3Department of Biology, Villanova University, Villanova, Pennsylvania, USA

4School of Biological Sciences, Monash University, Clayton, Victoria, Australia

5Institute of Biodiversity and Environmental Conservation, Universiti Malaysia Sarawak, Kota Samarahan, Malaysia

6Division of Natural Sciences, New College of Florida, Sarasota, Florida, USA

7Department of Terrestrial Zoology, Western Australian Museum, Welshpool, Western Australia, Australia

8Department of Biology, La Sierra University, Riverside, California, USA

9Department of Ecology and Evolutionary Biology, University of Michigan, Ann Arbor, Michigan, USA

10Environmental Futures Research Institute, Griffith University, Nathan, Queensland, Australia

11School of Science and Technology, Department of Biosciences, Nottingham Trent University, Nottingham, United Kingdom 12Faculty of Veterinary Science B01, University of Sydney, New South Wales, Australia

13Museo de Zoología, Escuela de Biología, Pontificia Universidad Católica del Ecuador, Quito, Ecuador

14Mitrani Department of Desert Ecology, The Jacob Blaustein Institutes for Desert Research, Ben-Gurion University of the Negev, Midreshet, Israel

\footnotetext{
Abstract

Aim. Clutch size is a key life-history trait. In lizards, it ranges over two orders of magnitude. The global drivers of spatial and phylogenetic variation in clutch have been extensively studied in birds, but such tests in other organisms are lacking. To test the generality of latitudinal gradients in clutch size, and their putative drivers, we present the first global-scale analysis of clutch sizes across of lizard taxa.

Location, Global

Time period. Recent

Major taxa studied. Lizards (Reptilia, Squamata, Sauria)

Methods. We analysed clutch-size data for over 3900 lizard species, using phylogenetic generalized leastsquare regression to study the relationships between clutch sizes and environmental (temperature, precipitation, seasonality, primary productivity, insularity) and ecological factors (body mass, insularity, activity times, and microhabitat use).

Results. Larger clutches are laid at higher latitudes and in more productive and seasonal environments. Insular taxa lay smaller clutches on average. Temperature and precipitation per se are unrelated to clutch sizes. In Africa, patterns differ from those on other continents. Lineages laying small fixed clutches are restricted to low latitudes.

Main conclusions. We suggest that the constraint imposed by a short activity season coupled with abundant resources is the main driver of large-clutch evolution at high latitudes and highly seasonal regions. We
} 
hypothesize that such conditions-which are unsuitable for species constrained to laying multiple small clutches-may limit the distribution of fixed-clutch taxa.

Key words

Ashmole's hypothesis, fecundity, fixed clutch size, geographic variation, Lack's rule, latitude, reproductive strategy, seasonality

\section{Introduction}

Reproductive effort is a critical component of animal life histories. How reproductive effort is allocated through a single reproductive event, over a breeding season, and over an entire lifespan, has major fitness consequences. Clutch size, laying frequency, length of the reproductive season, and reproductive lifespan can vary dramatically between and within taxa (Roff, 2002; Pincheira-Donoso and Hunt, 2017). Of these components, the number of offspring within a single clutch ('clutch size') probably varies most: from one to many millions of eggs in some invertebrates and anamniote vertebrates laying oligolecithal eggs (e.g., the brown crab, Cancer pagurus; Ungfors 2007; the sea hare, Aplysia californica; MacGinitie 1934; the cod, Gadus moruha; May, 1967; Lambert; 2008; see also Sadovy, 2001). In amniotes (birds, mammals, and reptiles) laying large, yolkladen macrolecithal eggs, clutch (and litter) size variation is narrower but clutches still range from one to $\sim 160$ eggs (Vitt and Caldwell, 2013).

Among squamates (lizards and snakes), clutch sizes vary across two orders of magnitude, from one to over 100 eggs in some large snakes (Reed and Rodda, 2009; Vitt and Caldwell, 2013) and to over 90 eggs in some chameleons (Tilbury, 2010; Zug, 2013; Meiri 2018). The causes underlying this enormous variation have inspired decades of research. Thus, clutch size and was found to be correlated with traits such as body size, growth rates, and longevity, supporting the notion of a fast-slow continuum (Tinkle et al., 1970; Dunham et al., 1988; Clobert et al., 1998; Pincheira-Donoso and Tregenza, 2011; Scharf et al. 2015). Clutch size was found to be negatively correlated with egg size and clutch frequency across multiple studies (e.g., In den Bosch and Bout, 1998; King, 2000; Amat, 2008; Meiri et al., 2012). In lizards, as in most ectotherms (Shine, 1988), clutch size has been repeatedly found to increase with increasing maternal body size (e.g., Tinkle et al., 1970; Dunham et al., 1988; Scharf and Meiri, 2013) - both within and between species. An exception is lineages where females only lay one or two eggs. The evolutionary correlates of such fixed clutch sizes (e.g., small body size, but large variation in egg sizes: Shine and Greer, 1991; Kratochvil and Kubicka, 2007; Meiri et al., 2015; Schwarz and Meiri, 2017) have been widely studied. The consequences of the transition to viviparity (reviewed in Shine, 2005; Murphy and Thompson, 2011; Sites et al., 2011; Pincheira-Donoso et al., 2013) for the number of offspring per reproductive event were widely studied (Huang, 2010; Meiri et al., 2020), generally finding no relationship between reproductive mode and brood size.

Compared to the multitude of studies exploring various biological drivers of clutch size variation, studies of geographic signals underlying clutch-size variation in most organisms, including squamates, remain scarce. In reptiles, some studies focused on reduction of clutch sizes with insularity (e.g., Huang, 2007; Siliceo and Diaz, 2010; Pafilis et al., 2011; Novosolov et al., 2013; Brandley et al., 2014; Slavenko et al., 2015), forested habitats (e.g., Werneck et al., 2009), and saxicolous and arboreal habits (Vitt, 1981; Schall, 1983; Mesquita et al. 2016). 
Few studies have addressed adaptive responses in reptile clutch size to global variation in climate. This is somewhat surprising as such climatic gradients in clutch size have been intensively studied in avian reptiles for well over a century. In fact, 75 years ago, Moreau (1944) wrote: "It is over a hundred years ago since the view was first put forward that, on the whole, tropical birds tend to lay fewer eggs than birds of the temperate zones". Birds lay larger clutches at higher latitudes and in colder, more seasonal environments (Rensch, 1938; Ricklefs, 1980). This has been shown repeatedly both within (e.g., Rensch, 1938; Moreau, 1944; Lack, 1947; Cody, 1966; Vaugoyeau et al., 2016) and among (e.g., Ricklefs, 1980; Jetz et al., 2008; Boyer et al., 2010; cf. Yom-Tov et al., 1994) species and clades.

In comparison, studies of geographic gradients in clutch size (excluding island effects) of other tetrapod taxa are few and far between, never quite achieving the paradigmatic status they have for birds (PincheiraDonoso \& Hunt, 2017). Morrison and Hero (2003) found that amphibian clutches are smaller at higher latitudes once maternal body sizes were accounted for. Studies of geographic trends in mammalian litter sizes are also uncommon (but see Virgos et al., 2006; Bywater et al., 2010). When large-scale comparative studies of squamate life histories have been carried out, geographic variation in clutch size was rarely the focus (e.g., Andrews and Rand 1974; Dunham et al., 1988; Clobert et al., 1998; Mesquita et al., 2016). Fitch (1985) found that clutch size increased with latitude within the six turtle species he studied, a result later corroborated by Iverson et al. (1993) based on a much larger sample. Fitch (1985) nonetheless claimed that snakes, and especially lizards, show much weaker trends. Clutch size was higher at higher latitudes in half (8 of 16) the lizard species he studied, seven species showed a reverse trend, and one showed none (Fitch 1985). The mean difference in clutch size between the high and low latitude populations was just $1 \%$. Interspecifically, Tinkle et al. (1970) found no differences between clutch sizes of tropical and temperate lizards, but Meiri et al. (2013), and Mesquita et al. (2016), identified significant, albeit weak, negative associations between clutch size and environmental temperatures.

Mechanisms responsible for observed geographic variation in clutch size have likewise mostly been studied in birds. Moreau (1944) hypothesized that increased winter mortality selects for large clutch sizes at high latitudes. Lack (1947) suggested that high-latitude birds benefit from longer days during the breeding seasons, enabling them to obtain more food. If valid, this mechanism is likely to hold for birds, a mostly diurnal clade, but for taxa with a more varied diel activity cycle it may mean that only clutches of diurnal species will increase with latitude. If true, clutch sizes may well decrease with latitude in nocturnal taxa, because nights during the summer activity season are short at high latitudes. Ashmole (1963), and Ricklefs (1980), hypothesized that high mortality rates, caused by increased seasonality, reduce population density at the beginning of each breeding season. They reasoned that this, coupled with abundant resources in the short breeding season, increases per-individual resource availability that can be channelled towards offspring production ("Ashmole's hypothesis"). Jetz et al. (2008) and Griebeler et al. (2010) likewise stressed the importance of juvenile and adult mortality, respectively, in selecting for a positive clutch-size/seasonality association in birds. Griebeler et al. (2010) suggested that increased predation pressure on chicks and adults at high latitudes could result in the observed pattern (but see Ricklefs 1980, Pincheira-Donoso \& Hunt 2017). Cooper et al. (2005) theorized that temperature may directly cause the observed patterns through its effect on incubation costs and survival. 
Importantly, nearly all the mechanisms suggested to account for the observed geographic variation in bird clutch sizes are likely to apply more generally across other organisms. Andrews and Rand (1974) further suggested that lizards in seasonal environments lay larger clutches than in aseasonal tropical regions. In the tropics, they suggested that short-term fluctuations in rainfall will favour frequent laying of small clutches. They claimed that arboreal lizards (especially those using adhesive toe pads) are constrained to lay small clutches because a large clutch of eggs would severely limit the climbing agility of the mother. Following a similar logic, Vitt (1981, see also Schwarzkopf et al. 2010), and Ashton (2005), suggested that saxicolous and fossorial species, respectively, will lay smaller clutches than terrestrial species - to better allow the pregnant mother to use rock fissures and narrow burrows.

Because there are no large-scale studies of geographic variation in clutch size of non-avian vertebrates, a global test of the environmental correlates of lizard clutch size could be insightful as well as timely. Using a global dataset of clutch sizes, we test a range of predictions regarding the evolutionary mechanisms influencing this important reproductive trait. We predict that lizard clutch sizes will be (1) positively correlated with latitude, and (2) positively correlated with temperature and precipitation seasonality. These three variables are probably good proxies for the length of the reproductive and activity seasons of lizards (see below), and-because predation is likely to be weakened when animals hibernate below grounds-perhaps also of mortality rates (Stark et al. 2018). If day length during the reproductive season (i.e., spring and summer for non-tropical lizards) affects clutch size (Lack 1947), we predict that (3) latitude will be positively correlated with clutch size in diurnal species but negatively associated with it in nocturnal species. We further predict (4) that in regions where resources are abundant, females will lay larger clutches because they can bear the energetic costs of doing so. We further examine the distribution of lizard lineages laying small, fixed clutches of one or two eggs relative to the distribution of lizards laying variable, usually larger, clutches. We attempt to infer (5) whether differences in their geographic distribution conform to the general relationship between clutch size and geographic distribution. Incidentally, we thus also test (6) whether clutch sizes increase with body mass (e.g., Dunham et al., 1988), (7) decrease with insularity (Novosolov et al., 2013), or (8) are lower in arboreal (Andrews and Rand 1974), fossorial (Ashton 2005) and saxicolous species than in terrestrial ones (Vitt 1981).

\section{Methods}

\section{Lizard clutch-size data}

We obtained data on lizard (Squamata exclusive of Serpentes) clutch size, body size, diurnal/nocturnal habits, and microhabitat preferences from the literature (e.g., Slavenko et al., 2016; Meiri, 2018, see Appendix 1 for a list of sources) and our personal observations in the field, laboratory, and natural-history collections. Some of the species in our database are viviparous, but Meiri et al. (2020) found no systematic differences between clutch sizes of oviparous squamates and litter sizes of viviparous ones. Hence we use the term 'clutch size' throughout, for simplicity, although live-bearing species are included. We used data on mean clutch sizes, and, when lacking means, we averaged the smallest and largest clutch sizes reported for a species. If multiple means were available we averaged the smallest and largest values (rather than average all means, because often a single mean is reported multiple times among studies, without proper acknowledgement). 
Body sizes (for testing Hypothesis 6) are mean snout-vent lengths (SVL's, in mm) of females, which we converted to masses using clade-specific allometric equations (from Feldman et al., 2016). Although within-taxon masses are highly variable (e.g., according to the time from and size of the last meal, body condition and whether a female is distended with eggs), in squamates, across squamate taxa masses better reflect size than lengths-as animals of identical length can easily vary by two orders of magnitude in mass (Meiri, 2010). Our clade-specific equations for legged, leg-reduced, and legless lizards separately take this shape variation into account and allow us to compare similar-sized taxa across the diversity in shape from long, thin pygopodids to chubby phrynosomatids (Feldman et al., 2016). As for clutch sizes, when multiple body size means were available, we averaged the smallest and largest values (Meiri, 2018). We classified lizards as either diurnal, nocturnal, or cathemeral (active during both day and night, including primarily nocturnal and primarily diurnal species) to test Hypothesis 3, and as terrestrial, fossorial, or scansorial (i.e., arboreal or saxicolous; Meiri 2018) to test Hypothesis 8. Species that frequently occur both on trees or rocks (as adults) and on the ground were also classified as scansorial because we assume the agility of a gravid female would be most greatly constrained by any climbing activity or when trying to lodge itself in rock crevices (Vitt, 1981, Schwarzkopf et al. 2010). Semi-aquatic species $(n=75)$ were classified as scansorial if they are also semi-arboreal or semisaxicolous (Grinham \& Norman, 2020), or as terrestrial otherwise. A preliminary analysis showed semi-aquatic species were not significantly different than either scansorial or terrestrial ones (not shown).

Species geographic ranges were obtained from Roll et al. (2017) with some subsequent updates (e.g., for newly described species). We used these distributional data to find species' latitudinal centroids in ESRI ArcGIS v.10.6 (ESRI, Redlands, California, USA; to test Hypotheses 1 \& 3) and measures of mean annual temperature (BIO1), temperature seasonality (BIO4) and precipitation seasonality (BIO15; to test Hypothesis 2). Climatic data are from CHELSA (Karger et al., 2017), and net primary productivity (=NPP) data are from Imhoff et al. (2004; Hypothesis 4). We calculated a single value per species for each climatic/environmental measure by averaging the climatic data across species' distributional ranges. Insular taxa were defined as those inhabiting only landmasses equal to or smaller than New Guinea, used to test Hypothesis 7. Taxonomy follows the December 2019 version of the Reptile Database (Uetz, 2019).

\section{Analyses}

To examine the relationship between clutch size and the climatic and other predictors we used specieslevel phylogenetic analyses. We log10-transformed clutch sizes and body masses, NPP, and temperature seasonality data to linearize relationships, improve residual normality, and reduce heteroscedasticity. We used the absolute value of the latitudinal centroid of each species. Multi-collinearity was minimal (the maximum VIF was 2.4, for temperature seasonality). Because latitude is a proxy for several climatic variables (and day length), however, we analysed latitude and climatic factors in separate models. To test whether diurnal and nocturnal species respond differently to climate (Hypothesis 3 ) we used two-way interactions between activity time and latitude. We then conducted a phylogenetic generalized-least squares ANCOVA (PGLS version of a Brownianmotion model of evolution; see Mesquita et al. 2016) using the caper R package (Orme et al., 2014), whereby the strength of the phylogenetic signal (using the $\lambda$ parameter) is assessed using maximum likelihood, and phylogenetic distances are multiplied by $\lambda$ before independent contrasts are calculated (Freckleton et al., 2002). 
We used the phylogenetic tree of squamates from Tonini et al. (2016) to calculate contrasts and distances. This tree is partially based on genetic data and partially inferred from taxonomy - some of which has become obsolete due to more recent genetic findings (SM, pers. obs.). We then ran two sets of PGLS models: one with mean female mass, insularity, microhabitat, activity time, mean annual temperature and its seasonality, mean annual precipitation and its seasonality and NPP as predictors; and another with mean female mass, insularity, microhabitat, activity time, latitude and the activity time/latitude interaction, as predictors of clutch size. Over 250 of the species in our dataset were not found in the tree of Tonini et al. (2016). Therefore, we added nonphylogenetic sensitivity analyses using an ANCOVA with the same predictors as in the PGLS. This could further allow us to assess if observed patterns result from evolutionary responses within taxa or from taxon turnover (Meiri and Thomas 2007, Novosolov and Meiri 2013).

We added two additional sensitivity analyses. First, our measure of body size was mean female body mass in the analyses described above. For 776 species, however, we had no data on mean female mass whereas we had data on maximum mass of all 3,916 species. To ensure that such a loss of $20 \%$ of the data did not bias our results we repeated the analyses with data on maximum body mass of all species (taken from either sex).

Within most lizard species, clutch sizes can be highly variable (e.g., 1-41 eggs in Elgaria multicarinata, 1-33 eggs in Cyclodomorphus gerrardii and Calotes versicolor, 2-77 eggs in Chamaeleo dilepis). In the Gekkota (geckos and flap-footed lizards), Gymnophthalmidae, and Dactyloidae (anoles), however, clutches are 'fixed', nearly always comprising just one or two eggs. Because species with fixed clutch sizes cannot, by definition, increase their clutch size in response to climate, we conducted analyses only for species that have variable clutch sizes, and again for all species (regardless of whether their clutch sizes are variable or fixed). We defined laying strategy based on phylogenetic affinities rather than basing it on observed clutch sizes. We designate all members of the Gekkota, Dactyloidae and Gymnophthalmidae as having fixed clutches even though clutch sizes of three or more eggs have been reported for a few of them. For example, the gecko, Mediodactylus kotschyi sometimes lays three eggs, although clutches of one or two eggs are much more common (Goldberg, 2012; Slavenko et al., 2015); nonetheless, we treated it as a fixed-clutch species. Species belonging to all other taxa were treated as having variable clutch sizes. This includes species that only lay one or two eggs. For example the agamid Draco bimaculatus, the amphisbaenian Cynisca leonina, and the lacertid Holaspis laevis, all have a maximum reported clutch size of two. They were treated as having variable clutch sizes because they belong to families in which most species lay larger clutches. We did this because we assume that 1-2 egg clutches in variable-clutch-sized lineages reflect ecologically induced selection pressures of the type we aim to identify here, whereas in fixed-clutched lineages such clutch sizes reflect constraints.

\section{Results}

We obtained clutch-size data for 3,916 lizard species. Mean clutch size per species varied between one (in 434 species) to 52 (in Chamaeleo senegalensis, $n=5$ individuals; Cisse and Karns 1978), with a mode of two eggs (1191 species; 1273 with mean clutch sizes of 1.9-2.1 eggs). All 44 lizard families are represented in our dataset, which covers $56 \%$ of global lizard diversity (3916 of 6950 recognized species; Appendix 1, Figure 1).

The results of the four types of global phylogenetic models (with either all species or just lizards with variable clutch sizes, and using either average female or maximum body mass) are highly congruent (Tables 1, 2, 
Appendix 2). Body mass is positively correlated with clutch size (Figure 2), which supports Hypothesis 6. Insular taxa lay fewer eggs, supporting Hypothesis 7; and fossorial (perhaps also scansorial) species have smaller clutch sizes than terrestrial species, supporting Hypothesis 8. Under more stringent criteria for assessing statistical significance (e.g., $p=0.005$, see Johnson, 2013, Benjamin et al., 2018), differences in clutch size among microhabitats are often not significant (Tables 1 and 2). Clutch sizes increase with latitude (supporting Hypothesis 1) and, in climatic models, increase with net temperature seasonality (Hypothesis 2) and primary productivity (Hypothesis 4), under any threshold for statistical significance and across all global tests. Clutch sizes increase with increased precipitation seasonality (Hypothesis 2) in taxa with variable clutch sizes, but patterns for precipitation seasonality are inconsistent across analyses (Appendix 2). Mean annual precipitation and mean annual temperature, however, are not related to clutch sizes (Table 1, Appendix 2). Activity time was generally unrelated to clutch size (see, e.g., ANOVA tables in Appendix 2), but it had a significant interaction with latitude in several models. Near the equator, nocturnal species have larger clutches than diurnal species, but clutch sizes of nocturnal taxa do not increase with latitude (or seasonality), whereas those of diurnal taxa do increase poleward (Figure 3; see Hypothesis 3, above). Because of the high similarity across models we discuss below the models using maximum body mass and only taxa with variable clutch sizes, highlighting other models only when they show different patterns.

Although in global analyses clutch sizes increase with latitude, in Africa they are larger at low latitudes (Figure 3, Appendix 2). We thus explored models for different biogeographic realms individually (Appendix 2). In the Afrotropical realm (which excludes the Sahara and Madagascar, but includes the southern parts of the Arabian Peninsula) clutch sizes do not respond to latitude (tested in taxa with variable clutch sizes, with maximum body mass as an additional predictor. Slope $=0.0020 \pm 0.0016, p=0.23, n=284$ ). Even in the Afrotropics, however, clutch sizes increase with temperature seasonality (Hypothesis 2 ; slope $=0.296 \pm 0.074, p$ $<0.0001$; but not with precipitation seasonality, slope $=0.0008 \pm 0.0005, p=0.16$; Appendix 2$)$. We suspected that the high clutch sizes in equatorial Africa were a result of the inclusion of chameleons. Chameleons are almost exclusively confined to Africa and Madagascar and have by far the largest clutches among all lizard families (13.4 eggs on average, not many more than the New World Iguanidae with 12.0, but chameleons are much smaller animals, and include many more species: 135 vs. 24 in our analyses; the family with the thirdlargest clutches, the Neotropical Polychrotidae, has an average clutch size of 9.0, n=7). However, omitting chameleons does not change the overall conclusion that lizard clutch sizes in Africa are large compared to other equatorial regions (Appendix 3 ).

Results of the non-phylogenetic models are very similar to those of the phylogenetic models except that, in the non-phylogenetic models for taxa with variable clutch sizes, scansorial species have similar values to terrestrial species (Appendix 2e). The important factors remain body mass (positive, Hypothesis 6), insularity (negative, Hypothesis 7), latitude (positive in diurnal species; hypotheses $1 \& 3$ ), seasonality (positive; especially for temperature seasonality; Hypothesis 2), and NPP (positive; Hypothesis 4 Appendix 2e).

\section{Discussion}

Our global-scale evidence reveals that lizard clutch sizes are larger at higher latitudes (Hypothesis 1) and in more seasonal environments. Lizard clutch sizes thus show similar geographic patterns to those seen in birds. 
Africa, however, emerges as a strong anomaly in lizards (Figure 3) but not in birds (see Figure 4a in Jetz et al., 2008). Lizard clutch sizes could thus be explained by similar mechanisms as those operating on birds (Jetz et al., 2008), suggesting the generality of these mechanisms beyond endotherms.

We are unaware of large-scale data on predation intensities that would allow us to assess whether predation too is higher in seasonal environments and higher latitudes (as hypothesized for birds by, e.g., Griebeler et al., 2010). The lack of temperature effects, however, leads us to conclude that seasonality (Hypothesis 2 ) is a stronger force than cold weather per se ('harshness', Morrongiello et al., 2012), at least in lizards. In highly seasonal environments, the window of opportunity for reproduction is short. Although temperature seasonality and latitude are but proxies for the length of the activity season of lizards (and also vary with other relevant factors), we think they are good proxies (see Appendix 4). High latitudes are often characterized by a high seasonal peak in environmental productivity (Geist, 1987; Huston and Wolverton, 2011), enabling lizards to produce large clutches. We posit that in such environments animals can both find sufficient resources, and are under strong selection pressure, to be as fecund as possible (Hypothesis 4).

There is another angle from which such results need to be viewed: What are the reasons that many species in stable, less-seasonal environments do not lay large clutches? The logical converse of our proposed explanation for high clutch sizes is that lizards in less-seasonal environments do not lay large clutches because environmental productivity lacks a seasonal peak. Under these circumstances it may take more time to accrue sufficient energetic resources to produce even one or two eggs. We hypothesize that laying few eggs in a single clutch may be advantageous as long as the female can compensate for the reduced number of eggs by laying more frequently (Meiri et al., 2013) - a requirement that stable environments allow for. Laying small, frequent clutches may be a safer bet if egg (or adult) predation pressure is high. Furthermore, there may be a high physiological strain on mothers laying large clutches (e.g., Blazquez et al., 2000; Pincheira-Donoso \& Hunt, 2017): carrying many eggs in the abdominal cavity may reduce locomotory performance and thereby increase predation risk, reduce foraging success, or convey additional energetic costs associated with carrying a heavy clutch of eggs (Vitt and Congdon, 1978). In some lizard taxa, the clutch may approach the weight of the mother (e.g., Diaz-Paniagua et al., 2002; Roitberg et al., 2013; Foster et al., 2019). Although this obviously also holds where seasons are short, in such regions the advantage of producing more eggs may outweigh the penalty paid for lower performance because producing multiple clutches each season is not a viable option.

The tendency of clutch sizes to be larger at higher latitudes (Hypothesis 1) and in more seasonal environments has been known for a long time, but only in birds has it received broad attention and the status of an ecological rule (sensu Mayr, 1956). The mechanisms suggested to explain this pattern, however, are hardly bird specific, as the evidence we present here shows. Of the suggested mechanisms we are aware of only the supposed additional costs of nesting and nestling mortality in cold regions (Cooper et al., 2005) may be specific to birds and probably irrelevant for lizards. We note that cold temperatures per se emerged in our models as unrelated to clutch size; thus, this mechanism really does not apply to lizards. Another hypothesis-that latitude is important as it relates to day length (Lack 1947) — suggests a difference between nocturnal and diurnal taxa. Perhaps most mammals, snakes, and owls, would show the reverse trends, though data are scant. Murray (1976) found that clutch sizes mostly increased northwards in seven species of North American owls, whereas Donázar (1990) did not find a pattern in the European Eagle owl. Interestingly, Evans et al. (2009) found that 
clutch size increased with day length in seven diurnal bird species in Britain, but decreased with day length (i.e., increased with night length) in the single owl in their study (Strix aluco). Consistent with this, we found that nocturnal and diurnal lizards differ in the relationship they show between clutch size and latitude. Diurnal lizard clutch sizes increase with latitude, whereas those of nocturnal lizards do not, as predicted by our Hypothesis 3 . Thus, at high latitudes during the spring and summer reproductive seasons, longer days may enable diurnal lizards to acquire more food or shuttle more efficiently between basking and foraging activities. Nocturnal lizards do not reach the highest latitudes that some diurnal species inhabit (Vidan et al., 2017), presumably because the short summer nights at high latitudes do not allow enough time to balance energetic requirements and/or the cold night-time temperatures do not allow for activity in most lizard lineages. Thus, variation in night length is lower for them at the low latitudes they inhabit, and they can reproduce year round. Furthermore, there are few nocturnal lizards with variable clutch sizes (93 species in our dataset), and, thus, the lack of a latitudinal effect on their reproduction may reflect low statistical power.

Africa emerges as a strong anomaly for the latitudinal clines we identify. Australia likewise seems to have lizards with relatively small clutch sizes for its latitudinal range and seasonality, and little within-continent variation (Fig. 3, but see Fig. S1). We cannot readily explain these unexpected anomalies - although the presence of many fossorial species in deserts of both continents could explain some of these patterns. We hypothesized that the mostly tropical, African-endemic, radiation of chameleons, with their huge clutches, could explain the large clutch sizes of tropical African lizards. We further reasoned that much of the pattern will disappear once body mass is accounted for, because variation in clutch size seemed to mirror body-mass variation in Africa (compare Figure 3 with Figure 1c in Slavenko et al., 2019). Removing chameleons from the analyses and accounting for body mass, however, still leaves us with an anomaly in Africa (Appendix 2, supplementary Figure S2). More research is needed to identify why this is so, and we note that our models still leave much unexplained variation (as do many models in ecology and evolution; Møller and Jennions 2002; Peek et al. 2003). For Australia, it may be that poor soils and low primary productivity (Hypothesis 4) constrain lizards to lay relatively small clutches. We note that, although clutch sizes in African lizards do increase with temperature seasonality, no factor except body mass (Hypothesis 6) emerged as related to lizard clutch size within Australia (Appendix 2). It may be that clutch size data for a larger proportion of African lizards are missing than for other regions (see also Tolley et al. 2016, Tingley et al. 2016). The lack of data is always a worry, though we have little reason to think these missing data would create systematic biases.

Birds and mammals are much better studied than reptiles generally (Bonnet et al., 2002; Donaldson et al., 2016; Meiri and Chapple, 2016; Troudet et al., 2017). It is therefore unsurprising that latitudinal variation in bird clutch sizes has been much more intensively studied than in reptiles. Interestingly, studies of geographic variation in litter sizes of mammals are few (but see Virgos et al., 2006; Bywater et al., 2010). Thus, words written over 80 years ago - "A corresponding rule of the litter-size of mammals is not yet sufficiently founded" (Rensch, 1938) - still ring true. Nonetheless, our study demonstrates that insights from the study of reptiles are not just interesting in their own right, but could inform more pervasive patterns. That patterns shown by birds and lizards are broadly similar suggests a wider generality across more taxa and perhaps similar mechanisms. Additional factors potentially affecting clutch sizes 
Our results support key predictions regarding other factors that affect clutch sizes. Clutch size increases with body mass (supporting Hypothesis 6) - most steeply when average female mass of taxa with variable clutch sizes is considered (Table B; the only analysis where the $95 \% \mathrm{Cl}$ of the slope includes the canonical 0.25 slope). Clutches are smaller on islands (Hypothesis 7), as expected under the predictions of the island syndrome (Adler and Levins, 1994; Covas, 2012; Pafilis et al., 2011; Novosolov et al., 2013), whereby life history is assumed to 'slow down' on islands. This pattern is consistent across phylogenetic and non-phylogenetic models and remains true when fixed-clutched taxa are excluded. Thus, we posit that this reflects, at least in part, an evolutionary response of insular lizards to the ecological settings they encounter (Hypothesis 7 ) rather than simply a matter of taxon turnover related to the greater propensity of geckos and anoles to colonize islands (Novosolov and Meiri, 2013). Strong intraspecific competition on islands (Judd and Ross, 1978; Melton, 1982; Adler and Levins, 1994; Novosolov et al., 2016; Itescu et al., 2017), in the face of lower predation and interspecific competition pressures, has been suggested to drive this. Interestingly, however, within insular taxa there does not seem to be an association between clutch size and island area (examining the largest island inhabited by a species; results not shown).

Microhabitat preferences were related to clutch size in many models (though not always significantly so, especially at $\alpha<0.005$; see Appendix 2). Scansorial species seem to lay smaller clutches than terrestrial species of similar sizes that inhabit similar regions. This agrees with Hypothesis 8 that carrying a large clutch of eggs can be a disadvantage to arboreal species, limiting the female's ability to climb (Andrews and Rand, 1974; Shine et al., 1998; Kratochvil and Kubicka, 2007). It also agrees with Vitt (1981), who found that some crevice-living species have small clutches, and who hypothesized that evolving large clutch sizes may prevent females from entering their retreats. Schwarzkopf et al. (2010) have shown experimentally that gravid females with larger clutch sizes had wider mid-bodies and required larger crevices.

We note, however, that most chameleons are arboreal, yet have the largest clutches of all lizards. Distinguishing between arboreal taxa, that respond to predators by fleeing (as most lizards do), rather than by camouflage (as most chameleons do), may prove illuminating. The prehensile tail of chameleons may also facilitate their ability to climb while gravid with large clutches. In our main analyses we designated all lizards that often climb rocks or vegetation as scansorial. We did not distinguish between strictly arboreal, strictly saxicolous, arboreal and saxicolous or even arboreal and terrestrial or terrestrial and saxicolous species, reasoning that climbing constrain the clutch sizes of all such species. In further analyses we found no significant differences between strictly terrestrial and strictly arboreal species, whereas species classified as both arboreal and saxicolous had slightly larger clutches than strictly arboreal ones (Appendix 5; see also Table 5 Mesquita et al. 2016, showing that semi-arboreal species have larger clutches than either saxicolous or arboreal ones).

Fossorial taxa emerged as having smaller clutches than terrestrial species in some models (Table 2, Appendix 2). Overall, our results add some evidence to support Ashton's (2005) claim that because the fossorial Plestiodon reynoldsi lays small clutches it is "similar to those of other fossorial lizards". We further note that within skinks (the only lizard clade with variable clutch sizes and multiple transitions to a fossorial lifestyle) fossoriality is indeed associated with small clutches (see Appendix 2 for within-clade models). We suspect this may be caused by increased energetic demand on burrowing for gravid females. Overall our results generally 
support the hypothesis that scansorial and fossorial lizards have smaller clutches than terrestrial ones, but effect sizes are generally small, and support varied across models.

The Geographic distribution of lizards with fixed and variable clutches

We have found that lizard clutches are generally larger in higher latitudes and in seasonal regions even when only taxa with variable clutch sizes are considered and when phylogenetic non-independence is accounted for (Figure 3). We note that the distribution of lizards with fixed clutch sizes would only serve to strengthen the generality of these patterns. Although taxa in which females lay only one or two eggs are, of course, not expected to show geographic variation in this parameter, they can nonetheless inform us about the relationship between clutch size and the environment. With the exception of a few gecko taxa (e.g., the New Zealand radiation, Nielsen et al., 2011; Cree and Hare, 2016; the South American Homonota darwini; Ibarguengoytia \& Casalins, 2007; Weeks and Espinoza, 2013), the distribution of fixed-clutch lizards is mostly limited to tropical, subtropical, and desert regions (geckos) or tropical and subtropical regions alone (anoles, gymnophthalmids; Roll et al., 2017). One could easily come up with hypotheses relating to the distribution of each of these three taxa. Gymnophthalmids, being mostly leaf-litter inhabitants, and anoles, being predominately scansorial (mostly arboreal, but with many leaf-litter species; e.g., Losos, 2009; Vitt and Caldwell, 2013), could perhaps not penetrate temperate desert belts and migrate further north. This, however, would not necessarily explain their absence from more temperate, higher latitudes south of the Equator in South America. Geckos, being predominately nocturnal (Bauer, 2013; Gamble et al., 2015), may be restricted largely to low latitudes by their inability to tolerate the cold nights prevailing at higher latitudes. Indeed Vidan et al. (2017) identified a sharp distinction between the distributions of Eurasian diurnal lizards, which could range above the Arctic Circle, and nocturnal taxa (mostly geckos), which do not reach anywhere near this far north. However, geckos have another trick up their sleeve: some of them evolved diurnal activity at colder regions, or bask during the day and forage at night (e.g., New Zealand Naultinus, Tarentola mauritanica in S. Europe, Ptyodactylus puiseuxi in northern Israel, and Quedenfeldtia in the Atlas Mountains; see, e.g., Gamble et al., 2015; Hare and Cree, 2016).

In the light of our findings, we tentatively suggest an alternative mechanism (Hypothesis 5): it may be that such taxa are restricted to low latitudes because their reproductive strategy - laying few eggs frequently - is simply not viable at higher latitudes (Figure 4). At high latitudes and other highly seasonal environments the reproductive season is short, and laying multiple clutches is thus not viable. It could be that fixed-clutch species are excluded from high latitudes and highly seasonal regions not because of cold climates but because the short activity seasons in those regions do not allow them to produce enough offspring to ensure population replacement. If this hypothesis is true it would suggest that evolving a fixed clutch size has implications beyond its immediate effects on reproduction. What are the proximal mechanisms constraining species to this strategy, and which ultimate mechanisms allow fixed-clutched lizards to thrive, are fascinating questions for future research.

In summary, lizard clutches are highly attuned to geographic cues, whether in the form of insularity or as climatic clines. It seems though, that rather than climate per se, lizard clutch sizes respond to the degree of seasonality through its effect on the number of opportunities for reproduction within a year and perhaps through seasonal effects on food abundance, mortality rates, and foraging opportunities. 


\section{Acknowledgements}

We thank Daniel Mesquita, Simon Baeckens and four anonymous referees for important comments on several earlier drafts of this manuscript. OTC thanks F.P. Ayala for his help gathering lizard reproductive data.

\section{Literature cited}

Adler, G. H. \& Levins, R. (1994). The island syndrome in rodent populations. Quarterly Review of Biology 69: 473-490.

Amat, F. (2008). Exploring female reproductive tactics: trade-offs between clutch size, egg mass and newborn size in lacertid lizards. Herpetological Journal 18: 147-153.

Andrews, R. M. \& Rand, A. S. (1974). Reproductive effort in anoline lizards. Ecology 55: 1317-1327.

Ashmole, N. P. (1963). The regulation of numbers of tropical oceanic birds. Ibis 103: 458-473.

Ashton, K. G. (2005). Life history of a fossorial lizard, Neoseps reynoldsi. Journal of Herpetology, 39: 389-395.

Bauer, A. M. (2013). Geckos. The animal answer guide. Johns Hopkins University Press. Baltimore.

Benjamin, D. J., Berger, J., Johannesson, M., Nosek, B. A., Wagenmakers, E.-J., ... Johnson, V. E. (2017). Redefine statistical significance. Nature Human Behaviour 2: 6-10.

Blazquez, M. C., Diaz-Paniagua, C. \& Mateo, J. A. 2000). Egg retention and mortality of gravid and nesting female chameleons in southern Spain. Herpetological Journal 10: 91-94.

Bywater, K. A, Apollonio, M., Cappai, N. \& Stephens, P. A. (2010). Litter size and latitude in a large mammal: the wild boar Sus scrofa. Mammal Review 40: 212-220.

Boyer, A. G., Cartron, J-L. E. \& Brown, J. H. (2010). Interspecific pairwise relationships among body size, clutch size and latitude: deconstructing a macroecological triangle in birds. Journal of Biogeography 37: 47-56.

Bonnet, X., Shine, R. \& Lourdais, O. (2002). Taxonomic chauvinism. Trends in Ecology and Evolution 17: 1-3.

Brandley, M. C., Kuriyama, T. \& Hasegawa, M. (2014). Snake and bird predation drive the repeated convergent evolution of correlated life history traits and phenotype in the Izu Island scincid lizard (Plestiodon latiscutatus). PLoS ONE 9(3): e92233.

Cisse, M. \& Karns, D. R. (1978). Saurians from Senegal. Bulletin de l'institut Fondamental d'Afrique Noire Serie A Sciences Naturelles, 40: 144-211.

Clobert, J., Garland, T. \& Barbault, R. (1998). The evolution of demographic tactics in lizards: a test of some hypotheses concerning life history evolution. Journal of Evolutionary Biology 11: 329-364.

Cody, M. L. 1966. A general theory of clutch size. Evolution, 20: 174-184.

Cooper, C. B., Hochahka, W. M., Butcher, G \& Dhondt, A. A. (2005). Seasonal and latitudinal trends in clutch size: Thermal constraints during laying and incubation. Ecology, 86: 2018-2031.

Covas, R. (2012). Evolution of reproductive life histories in island birds worldwide. Proceedings of the Royal Society of London B. 279: 1531-1537.

Cree, A. \& Hare, K. M. (2016). Reproduction and life history of New Zealand lizards. Pages 169-206 in Chapple, D. G. Editor. New Zealand lizards. Springer, New York.

Diaz-Paniagua, C., Cuadrado, M., Blazquez, M. C. \& Mateo, J. A. (2002). Reproduction of Chamaeleo chamaeleon under contrasting environmental conditions. Herpetological Journal, 12: 99-104. 
Donaldson, M. R., Burnett, N. J., Braun, D. C., Suski, C. D., Hinch, S. G., Cooke, S. J. \& Kerr, J. T. (2016). Taxonomic bias and international biodiversity conservation research. Facets, 1: 105-113.

Donázar, J. A. (1990). Geographic variation in clutch and brood size of the Eagle Owl Bubo bubo in the Western Palearctic. Journal für Ornithologie, 131: 439-443.

Dunham, A. E., Miles, D. B. \& Reznick, D. N. (1988). Life history patterns in squamate reptiles. Pages 441-522 in C. Gans \& R. B. Huey, eds. c. Ecology B. Defense and life history. Liss, New York.

Evans, K.L., Leech, D.I., Crick, H.Q., Greenwood, J. J. and Gaston, K. J. 2009. Latitudinal and seasonal patterns in clutch size of some single-brooded British birds. Bird Study, 56: 75-85.

Feldman, A., Sabath, N., Pyron, R. A., Mayrose, I. \& Meiri, S. (2016). Body-sizes and diversification rates of lizards, snakes, amphisbaenians and the tuatara. Global Ecology and Biogeography 25: 187-197.

Fitch, H. S. (1985). Variation in clutch and litter size in New World reptiles. University of Kansas Museum of Natural History Miscellaneous Publications 76: 1-76.

Foster, C. D., Sharp, S., Greene, S. \& Tietgen, M. (2019). Husbandry and breeding of the Baja blue rock lizard (Petrosaurus thalassinus) at the Arizona Center for Nature Conservation's Phoenix Zoo. Herpetological Review 50: 79-83.

Freckleton, R. P., Harvey, P. H. and Pagel, M. (2002). Phylogenetic dependence and ecological data: a test and review of evidence. The American Naturalist, 160: 716-726.

Gamble, T., Greenbaum, E., Jackman, T. R. \& Bauer, A. M. (2015). Into the light: diurnality has evolved multiple times in geckos. Biological Journal of the Linnean Society 115: 896-910.

Geist, V. (1987). Bergmann's rule is invalid. Canadian Journal of Zoology 65: 1035-1038.

Goldberg, S. R. (2012). Reproduction in Kotschy's gecko Mediodactylus kotschyi (Squamata: Gekkonidae) from the Greek islands and Israel. The Herpetological Bulletin 119: 15-18.

Griebeler, E. M., Caprano, T. and Bohning-Gaese, K. (2010). Evolution of avian clutch size along latitudinal gradients: do seasonality, nest predation or breeding season length matter? Journal of Evolutionary Biology 23: 888-901.

Grinham, L. R. and Norman, D. B. (2020) The pelvis as an anatomical indicator for facultative bipedality and substrate use in lepidosaurs. Biological Journal of the Linnean Society 129: 398-413. doi:

10.1093/biolinnean/blz190

Hare, K. M. \& Cree, A. (2016). Thermal and metabolic physiology of New Zealand lizards. Pages 239-267 in Chapple, D. G. Editor. New Zealand lizards. Springer, New York.

Huang, W-S. (2007). Ecology and reproductive patterns of the agamid lizard Japalura swinhonis on an East Asian island, with comments on the small clutch sizes of island lizards. Zoological Science, 24: 181-188. Huang, W-S. (2010). Ecology and reproductive characteristics of the skink Sphenomorphus incognitus on an East Asian island, with comments on variations in clutch size with reproductive modes in Sphenomorphus. Zoological Studies 49: 779-788.

Huston, M. A. \& Wolverton, S. (2011). Regulation of animal size by eNPP, Bergmann's rule, and related phenomena. Ecological Monographs, 81: 349-405. 
Ibarguengoytia, N. R. \& Casalins, L. (2007) Reproductive biology of the southernmost gecko Homonota darwini: convergent life-history patterns among southern hemisphere reptiles living in harsh environments. Journal of Herpetology 41: 71-79.

Imhoff, M. L., Bounoua, L., Ricketts, T., Loucks, C.. Harriss, R. \& Lawrence, W. T. (2004). Global patterns in human consumption of net primary production. Nature 429: 870-873.

In den Bosch, H. A. J. and Bout, R. G. (1998). Relationships between maternal size, egg size, clutch size and hatchling size in European lacertid lizards. Journal of Herpetology, 32: 410-417.

Itescu, I., Schwarz, R., Meiri, S. \& Pafilis, P. (2017). Intra-specific competition, not predation, drives lizard tail loss on islands. Journal of Animal Ecology 86: 66-74.

Iverson, J. B., Balgooyecn. P., Byrdk, K. \& Lyddank, K. (1993). Latitudinal variation in egg and clutch size in turtles. Canadian Journal of Zoology 71: 2448-2461.

Jetz, W., Sekercioglu, C. H. \& Bohning-Gaese, K. (2008). The worldwide variation in avian clutch size across species and space. PLoS Biology 6: e303.

Johnson, V. E. (2013). Revised standards for statistical evidence. Proceedings of the National Academy of Sciences, USA 110: 19175-19176.

Judd, F. W. \& Ross, R. K. (1978). Year-to-year variation in clutch size of island and mainland populations of Holbrookia propinqua (Reptilia, Lacertilia, Iguanidae). Journal of Herpetology 12: 203-207.

Karger, D. N., Conrad, O., Böhner, J., Kawohl, T., Kreft, H., Soria-Auza, R.W.... Kessler, M. (2017)

Climatologies at high resolution for the Earth's land surface areas. Scientific Data 4, 170122.

King, R. B. (2000). Analyzing the relationship between clutch size and female body size in reptiles. Journal of Herpetology 34: 148-150.

Kratochvil, L. \& Kubicka, L. (2007). Why reduce clutch size to one or two eggs? Reproductive allometries reveal different evolutionary causes of invariant clutch size in lizards. Functional Ecology 21: 171-177.

Lack, D. (1947). The significance of clutch-size. Ibis, 89: 302-352.

Lambert, Y., (2008). Why should we closely monitor fecundity in marine fish populations. Journal of Northwest Atlantic Fishery Science 41, pp.93-106.

Losos, J. B. (2009). Lizards in an evolutionary tree: ecology and adaptive radiation of Anoles. University of California Press, Berkeley.

MacGinitie, G. E. (1934). The egg-laying activities of the sea hare, Tethys californicus (Cooper). The Biological Bulletin, 67: 300-303.

May, A.W. (1967). Fecundity of Atlantic cod. Journal of the Fisheries Board of Canada, 24: 1531-1551.

Mayr, E. (1956). Geographical character gradients \& climatic adaptation. Evolution 10: 105-108.

Meiri, S. (2010) Length-weight allometries in lizards. Journal of Zoology 281: 218-226.

Meiri, S. (2018). Traits of lizards of the world - variation around a successful evolutionary design. Global Ecology and Biogeography 27: 1168-1172.

Meiri, S. \& Chapple, D. G. (2016). Biases in the current knowledge of threat status in lizards, and bridging the 'assessment gap'. Biological Conservation, 204A: 6-15.

Meiri, S. and Thomas, G. H. (2007). The geography of body size - challenges of the interspecific approach. Global Ecology and Biogeography 16: 689-693. 
Meiri, S., Brown, J. H. \& Sibly, R. M. (2012). The ecology of lizard reproductive output. Global Ecology and Biogeography 21: 592-602.

Meiri, S., Bauer, A. M., Chirio, L., Colli, G. R., Das, I., Doan, T. M... Van Damme, R. (2013). Are lizards feeling the heat? A tale of ecology and evolution under two temperatures. Global Ecology and Biogeography 22: 834-845.

Meiri, S., Feldman, A. \& Kratochvil, L. (2015). Squamate hatchling size and the evolutionary causes of negative offspring size allometry. Journal of Evolutionary Biology 28: 438-446.

Meiri, S., Feldman, F., Schwartz, R. and Shine, R. 2020. Viviparity does not affect the numbers and sizes of reptile offspring. Journal of Animal Ecology, 89: 360-369. https://doi.org/10.1111/1365-2656.13125.

Melton, R. H. (1982). Body size and island Peromyscus: A pattern and a hypothesis. Evolutionary Theory 6: 113126.

Mesquita, D. O., Costa, G. C., Colli, G. R., Costa, T. B., Shepard, D. B., Vitt, L. J. \& Pianka, E. R. (2016). Lifehistory patterns of lizards of the world. The American Naturalist 187: 689-705.

Møller, A. P. and Jennions, M. D. 2002. How much variance can be explained by ecologists and evolutionary biologists? Oecologia 132: 492-500.

Moreau, R. (1944). Clutch size: A comparative study, with special reference to African birds. Ibis, 86: 286-347.

Morrison, C. \& Hero, J. M. (2003). Geographic variation in life-history characteristics of amphibians: a review. Journal of Animal Ecology, 72: 270-279.

Morrongiello, J. R., Bond, N. R., Crook, D. A. \& Wong, B. (2012). Spatial variation in egg size and egg number reflects trade-offs and bet-hedging in a freshwater fish. Journal of Animal Ecology, 81: 806-817.

Murphy, B. F. and Thompson, M. B. (2011). A review of the evolution of viviparity in squamate reptiles: the past, present and future role of molecular biology and genomics. Journal of Comparative Physiology B 181: 575594.

Murray, G. A. (1976). Geographic variation in the clutch sizes of seven owl species. The Auk, 93: 602-613.

Nielsen, S.V., Bauer, A.M., Jackman, T.R., Hitchmough, R.A. \& C.H. Daugherty. (2011). New Zealand geckos (Diplodactylidae): cryptic diversity in a post-Gondwanan lineage with trans-Tasman affinities. Molecular Phylogenetics and Evolution 59: 1-22.

Novosolov, M. \& Meiri, S. (2013). The effect of island type on lizard reproductive traits. Journal of Biogeography, 40: 2385-2395.

Novosolov, M., Raia, P. \& Meiri, S. (2013). The island syndrome in lizards. Global Ecology and Biogeography, 22: 184-191.

Novosolov, M., Rodda, G. H., Feldman, A., Kadison, A. E., Dor, R. \& Meiri, S. (2016). Power in numbers. The evolutionary drivers of high population density in insular lizards. Global Ecology and Biogeography, 26: 8795.

Orme, D., Freckleton, R., Thomas, G., Petzoldt, T., Fritz, S., Isaac, N. and Pearse, W. 2014. Caper: Comparative analyses of phylogenetics and evolution in $R$. R package version 0.5.2/r121. http://R-Forge.Rproject.org/projects/caper/ 
Pafilis, P., Foufopoulos, J., Sagonas, K., Runemark, A., Svensson, E., \& Valakos, E. D. (2011). Reproductive biology of insular reptiles: marine subsidies modulate expression of the "island Syndrome". Copeia, 2011: 545-552.

Peek, M. S., Leffler, A. J., Flint, S. D. and Ryel, R. J. 2003. How much variance is explained by ecologists? Additional perspectives. Oecologia, 137: 161-170.

Pincheira-Donoso, D. \& Hunt, J. (2017). Fecundity selection theory: concepts and evidence. Biological Reviews 92: 341-356.

Pincheira-Donoso, D. \& Tregenza, T. (2011). Fecundity selection and the evolution of reproductive output and sex-specific body size in the Liolaemus lizard adaptive radiation. Evolutionary Biology 38: 197-207.

Pincheira-Donoso, D., Tregenza, T., Witt, M. J. \& Hodgson, D. J. (2013). The evolution of viviparity opens opportunities for lizard radiation but drives it into a climatic cul-de-sac. Global Ecology and Biogeography 22: 857-867.

Reed, R. N. \& Rodda, G. H. (2009). Giant constrictors: biological and management profiles and an establishment risk assessment for nine large species of pythons, anacondas, and the boa constrictor (No. 2009-1202). US Geological Survey.

Rensch, B. (1938). Some problems of geographical variation and species formation. Proceedings of the Linnean Society of London 150: 275-285.

Ricklefs, R. E. (1980). Geographical variation in clutch size among passerine birds: Ashmole's hypothesis. Auk 97: 38-49.

Roff, D. A. (2002). Life history evolution. Sinauer Associates, Sunderland.

Roitberg, E. S., Kuranova, V. N., Bulakhova, N. A., Orlova, V. F., Eplanova, G. V., Zinenko, O... Yakovlev, V. A. (2013). Variation of reproductive traits and female body size in the most widely-ranging terrestrial reptile: testing the effects of reproductive mode, lineage, and climate. Evolutionary Biology 40: 420-438.

Roll, U., Feldman, A., Novosolov, M., Allison, A., Bauer, A., Bernard, R., ... Meiri, S. (2017). The global distribution of tetrapods reveals a need for targeted reptile conservation. Nature Ecology \& Evolution 1: $1677-$ 1682.

Sadovy, Y. (2001). The threat of fishing to highly fecund fishes. Journal of Fish Biology, 59: 90-108.

Schall, J. J. (1983). Small clutch size in a tropical whiptail lizard (Cnemidophorus arubensis). Journal of Herpetology 17: 406-408.

Scharf, I. \& Meiri, S. (2013). Sexual dimorphism of heads and abdomens: different approaches to 'being large' in female and male lizards. Biological Journal of the Linnean Society 110: 665-673.

Scharf, I., Feldman, A., Novosolov, M., Pincheira-Donoso, D., Das, I., Bohm, M.... Meiri, S. (2015). Late bloomers and baby boomers: ecological drivers of longevity in squamates and the tuatara. Global Ecology and Biogeography 24: 396-405.

Schwarz, R. \& Meiri, S. (2017). The fast-slow life-history continuum in insular lizards: A comparison between species with invariant and variable clutch sizes. Journal of Biogeography 44: 2808-2815.

Schwarzkopf, L., Barnes, M. \& Goodman, B. (2010). Belly up: Reduced crevice accessibility as a cost of reproduction caused by increased girth in a rock-using lizard. Austral Ecology 35: 82-86. 
Shine, R. (1988). The evolution of large body size in females: a critique of Darwin's "fecundity advantage" model. The American Naturalist 131: 124-131.

Shine, R. (2005). Life-history evolution in reptiles. Annual Review of Ecology and Systematics 36: 23-46.

Shine, R. \& Greer, A. E. (1991). Why are clutch sizes more variable in some species than in others? Evolution 45: 1696-1706.

Shine, R., Keogh, J. S., Doughty, P. \& Giragossyan, H. (1998). Costs of reproduction and the evolution of sexual dimorphism in a 'flying lizard' Draco melanopogon (Agamidae). Journal of Zoology 246: 203-213.

Siliceo, I. \& Diaz, J. A. (2010). A comparative study of clutch size, range size, and the conservation status of island vs. mainland lacertid lizards. Biological Conservation 143: 2601-2608.

Sites, J. W., Reeder, T. W. and Wiens, J. J. (2011). Phylogenetic insights on evolutionary novelties in lizards and snakes: sex, birth, bodies, niches, and venom. Annual Review of Ecology, Evolution, and Systematics 42: 227-244.

Slavenko, A., Itescu, Y., Foufopoulos, J., Pafilis, P. \& Meiri, S. (2015). Clutch size variability in an ostensibly fixed-clutch lizard: effects of insularity on a Mediterranean gecko. Evolutionary Biology, 42: 129-136.

Slavenko, A., Tallowin, O. J. S., Itescu, Y., Raia, P. \& Meiri, S. (2016). Late Quaternary reptile extinctions: size matters, insularity dominates. Global Ecology and Biogeography 25: 1308-1320.

Slavenko, A., Feldman, A., Allison, A., Bauer, A. M., Böhm, M., Chirio, L... Meiri, S. (2019). Global patterns of body size evolution in squamate reptiles are not driven by climate. Global Ecology and Biogeography 28: 471-483.

Stark, G., Tamar, K., Itescu, Y., Feldman, A. \& Meiri, S. (2018) Cold and isolated ectotherms: drivers of reptilian longevity. Biological Journal of the Linnean Society 125: 730-740.

Tilbury, C. (2010). Chameleons of Africa. An atlas. Including the chameleons of Europe, the Middle East, and Asia. Edition Chimaira, Frankfurt Am Main.

Tinkle, D. W., Wilbur, H. M. \& Tilley, S. G. (1970). Evolutionary strategies in lizard reproduction. Evolution, 24: 55-74.

Tonini, J. F. R., Beard, K. H., Ferreira, R. B., Jetz, W. and Pyron, R. A. (2016). Fully-sampled phylogenies of squamates reveal evolutionary patterns in threat status. Biological Conservation 204: 23-31.

Troudet, J., Grandcolas, P., Blin, A., Vignes-Lebbe, R. and Legendre, F. (2017). Taxonomic bias in biodiversity data and societal preferences. Scientific Reports, 7: 9132.

Uetz, P. (2019). The reptile database, http://reptile-database.reptarium.cz, accessed December 25 $5^{\text {th }}, 2019$.

Ungfors, A., 2007. Sexual maturity of the edible crab (Cancer pagurus) in the Skagerrak and the Kattegat, based on reproductive and morphometric characters. ICES Journal of Marine Science, 64(2), pp.318-327.

Vaugoyeau, M., Adriaensen, F., Artemyev, A., Banbura, J., Barba, E. et al., (2016). Interspecific variation in the relationship between clutch size, laying date and intensity of urbanization in four species of hole-nesting birds. Ecology and Evolution, 6: 5907-5920.

Vidan, E., Roll, U., Bauer, A. M., Grismer, L. L., Guo, P., Maza, E... Meiri, S. (2017). The Eurasian hot nightlife environmental forces associated with nocturnality in lizards. Global Ecology and Biogeography 26: 13161325. 
Virgos, E., Cabezas-Diaz, S. \& Blanco-Aguiar, J. A. (2006). Evolution of life history traits in Leporidae: a test of nest predation and seasonality hypotheses. Biological Journal of the Linnean Society 88: 603-610.

Vitt, L. J. (1981). Lizard reproduction: habitat specificity and constraints on relative clutch mass. The American Naturalist, 117: 506-514.

Vitt, L. J. \& Caldwell, J. P. (2013). Herpetology. $4^{\text {th }}$ Edition, Elsevier, London.

Vitt, L. J. \& Congdon, J. D. (1978). Body shape, reproductive effort, and relative clutch mass in lizards: resolution of a paradox. The American Naturalist 112: 595-608.

Weeks, D. M. \& Espinoza, R. E. (2013). Lizards on ice: Comparative thermal tolerances of the world's southernmost gecko. Journal of Thermal Biology 38: 225-232.

Werneck, F. D. P., Giugliano, L. G., Colleavtti, R. G. \& Colli, G. (2009). Phylogeny, biogeography and evolution of clutch size in South American lizards of the genus Kentropyx (Squamata: Teiidae). Molecular Ecology 18: 262-278.

Yom-Tov, Y., Christie, M.I. \& Iglesias, G.J., (1994). Clutch size in passerines of southern South America. Condor, 96: 170-177.

Zug, G. R. (2013). Reptiles and amphibians of the Pacific islands: a comprehensive guide. University of California Press, Berkeley.

\section{Data Accessibility Statement:}

All data used in the analyses are available as Appendix 1. 


\section{Tables}

Table 1. ANOVA results and parameter estimates of clutch sizes as a function of ecological and geographical predictors. For full results see Appendix 2.
A. ANOVA tables, all taxa, maximum body mass; a model with NPP and precipitation followed by model with latitude
B. Parameter estimates, all taxa, maximum body mass
C. ANOVA table, taxa with variable clutch sizes, maximum body mass
D. Parameter estimates, taxa with variable clutch sizes, maximum body mass

A.

1. ANOVA table, climatic model

\begin{tabular}{|c|c|c|c|c|c|}
\hline & Df & $\begin{array}{l}\text { sum of } \\
\text { squares }\end{array}$ & $\begin{array}{l}\text { mean } \\
\text { squares }\end{array}$ & $\mathrm{F}$ & $p$ \\
\hline Body Mass & 1 & 0.271 & 0.271 & 774.512 & $<0.0001$ \\
\hline Insularity & 1 & 0.033 & 0.033 & 93.108 & $<0.0001$ \\
\hline Microhabitat & 2 & 0.004 & 0.002 & 5.411 & 0.005 \\
\hline Precipitation seasonality & 1 & 0.003 & 0.003 & 7.469 & 0.006 \\
\hline Temperature seasonality & 1 & 0.025 & 0.025 & 71.423 & $<0.0001$ \\
\hline NPP & 1 & 0.013 & 0.013 & 38.149 & $<0.0001$ \\
\hline Residuals & 3425 & 1.198 & 0.0004 & & \\
\hline
\end{tabular}

2. ANOVA table, latitude model

$\begin{array}{llllll}\text { Factor } & \text { Df } & \begin{array}{l}\text { sum of } \\ \text { squares }\end{array} & \begin{array}{l}\text { mean } \\ \text { squares }\end{array} & F & p \\ \text { Body Mass } & 1 & 0.252 & 0.252 & 693.800 & <0.0001 \\ \text { Insularity } & 1 & 0.029 & 0.029 & 78.450 & <0.0001 \\ \text { Microhabitat } & 2 & 0.005 & 0.002 & 6.318 & 0.002 \\ \text { Activity time } & 2 & 0.0009 & 0.0004 & 1.177 & 0.308 \\ \text { Latitude } & 1 & 0.015 & 0.015 & 40.794 & <0.0001 \\ \text { Activity time: Latitude interaction } & 2 & 0.004 & 0.002 & 5.500 & 0.004 \\ \text { Residuals } & 3228 & 1.17365 & 0.00036 & & \end{array}$


B. Parameter estimates, all taxa, maximum body mass

1. Parameter estimates, climate and NPP model

$\begin{array}{lllll}\text { Factor } & \text { Estimate } & \mathrm{SE} & \mathrm{t} & \mathrm{p} \\ \text { Terrestrial } & 0.420 & 0.146 & -5.651 & <0.0001 \\ \text { Fossorial } & 0.392 & 0.147 & -2.131 & 0.0331 \\ \text { Scansorial } & 0.405 & 0.147 & -2.152 & 0.0314 \\ \text { Mainland } & 0.420 & 0.010 & -3.337 & 0.0009 \\ \text { Insular } & 0.389 & 0.144 & -5.974 & <0.0001 \\ \text { Mass } & 0.176 & 0.006 & 27.943 & <0.0001 \\ \text { Precipitation seasonality } & 0.0003 & 0.0001 & 2.716 & 0.0066 \\ \text { Temperature seasonality } & 0.119 & 0.012 & 10.041 & <0.0001 \\ \text { NPP } & 0.057 & 0.009 & 6.177 & <0.0001\end{array}$

All species, maximum body mass, lambda $=0.776$, model $R^{2}=0.225$. Mass, seasonality and NPP estimates are slopes (log 10 transformed except precipitation seasonality). Values (clutch sizes, log 10 transformed) of the categorical variables are for the means of the continuous predictors: a mass of $12.3 \mathrm{~g}$ (back transformed from logarithm), $\log$ NPP $=11.37\left(\mathrm{~g} \mathrm{C} \mathrm{m}^{-2}, \mathrm{yr}^{-1}, \log 10\right.$ transformed), Temperature seasonality = 3.3 (standard deviation, ${ }^{\circ} \mathrm{C}^{*} 100$, log 10 transformed), precipitation seasonality $=66.3$ (coefficient of variation of monthly values). Values for microhabitats are shown for mainland species. Values for insularity/mainland are shown for terrestrial species. Estimates are presented with their standard errors. $t$ and $p$ values are for differences from zero (with the continuous variables set to zero) for terrestrial and mainland species, from terrestrial species for fossorial and scansorial ones, and from insular species from mainland species.

Terrestrial species have smaller clutches than both scansorial and fossorial species. There are no significant differences between scansorial and fossorial species $(t=0.923, p=0.356)$.

2. Parameter estimates, latitude and activity time model

$\begin{array}{lllll}\text { Factor } & \text { Estimate } & \text { se } & \mathrm{t} & \mathrm{p} \\ \text { Terrestrial } & 0.475 & 0.083 & 2.737 & 0.006 \\ \text { Fossorial } & 0.433 & 0.084 & 2.721 & 0.0065 \\ \text { Scansorial } & 0.456 & 0.083 & 2.581 & 0.0099 \\ \text { Mainland } & 0.475 & 0.083 & 2.737 & 0.006 \\ \text { Insular } & 0.408 & 0.083 & 1.926 & 0.054 \\ \text { Latitude (diurnal species) } & 0.0031 & 0.0004 & 7.179 & <0.0001 \\ \text { Latitude (nocturnal species) } & 0.001 & 0.001 & 0.671 & 0.502 \\ \text { Mass } & 0.170 & 0.007 & 26.142 & <0.0001\end{array}$


All species, maximum body mass, lambda $=0.794$, model $R^{2}=0.206$. Mass (log 10 transformed) and latitude estimates are slopes. Values (clutch sizes, log 10 transformed) of the categorical variables are for the means of the continuous predictors: a mass of $12.3 \mathrm{~g}$ (back transformed from logarithm), latitude (absolute value): $19.55^{\circ}$ (decimal). Values for microhabitats are shown for diurnal mainland species. Values for insularity/mainland are shown for diurnal terrestrial species. Estimates are presented with their standard errors; $t$ and $p$ values are for differences from zero (with mass and latitude set to zero) for terrestrial and mainland species, from terrestrial species for fossorial and scansorial ones, and from insular species from mainland species. Terrestrial species have smaller clutches than both scansorial and fossorial species but there are no significant differences between scansorial and fossorial species $(t=1.383, p=0.167)$. Latitudinal slope for cathemeral species not shown. 
C. taxa with variable clutch sizes, maximum body mass

1. ANOVA table, climatic model

$\begin{array}{llllll}\text { Factor } & \text { Df } & \begin{array}{l}\text { sum of } \\ \text { squares }\end{array} & \begin{array}{l}\text { mean } \\ \text { squares }\end{array} & \mathrm{F} & \mathrm{p} \\ \text { Body Mass } & 1 & 0.324 & 0.324 & 654.103 & <0.0001 \\ \text { Insularity } & 1 & 0.047 & 0.047 & 94.249 & <0.0001 \\ \text { Microhabitat } & 2 & 0.004 & 0.002 & 3.811 & 0.022 \\ \text { Precipitation seasonality } & 1 & 0.006 & 0.006 & 11.588 & 0.001 \\ \text { Temperature seasonality } & 1 & 0.029 & 0.029 & 58.862 & <0.0001 \\ \text { NPP } & 1 & 0.025 & 0.025 & 51.457 & <0.0001 \\ \text { Residuals } & 2196 & 1.086 & 0.000 & & \end{array}$

2. ANOVA table, latitude model

$\begin{array}{llllll}\text { Factor } & \text { Df } & \begin{array}{l}\text { sum of } \\ \text { squares }\end{array} & \begin{array}{l}\text { mean } \\ \text { squares }\end{array} & F & p \\ \text { Body Mass } & 1 & 0.310 & 0.310 & 568.559 & <0.0001 \\ \text { Insularity } & 1 & 0.045 & 0.045 & 82.018 & <0.0001 \\ \text { Microhabitat } & 2 & 0.004 & 0.002 & 4.055 & 0.017 \\ \text { Activity time } & 2 & 0.002 & 0.001 & 1.557 & 0.211 \\ \text { Latitude } & 1 & 0.016 & 0.016 & 29.321 & <0.0001 \\ \text { Activity time: Latitude interaction } & 2 & 0.002 & 0.001 & 1.444 & 0.236 \\ \text { Residuals } & 2013 & 1.097 & 0.001 & & \end{array}$

D. taxa with variable clutch sizes, maximum body mass

1. Parameter estimates, climate and NPP model

$\begin{array}{lllll}\text { Factor } & \text { Estimate } & \mathrm{SE} & \mathrm{t} & \mathrm{p} \\ \text { Terrestrial } & 0.499 & 0.211 & -6.967 & <0.0001 \\ \text { Fossorial } & 0.471 & 0.210 & 1.0645 & 0.100 \\ \text { Scansorial } & 0.483 & 0.211 & 1.0673 & 0.094 \\ \text { Mainland } & 0.499 & 0.211 & -6.967 & <0.0001 \\ \text { Insular } & 0.464 & 0.206 & -7.319 & <0.0001 \\ \text { Mass } & 0.216 & 0.008 & 25.585 & <0.0001 \\ \text { Precipitation seasonality } & 0.0006 & 0.0001 & 3.846 & 0.0001 \\ \text { Temperature seasonality } & 0.169 & 0.017 & 9.896 & <0.0001\end{array}$


NPP

0.096

$0.013 \quad 7.173$

$<0.0001$

Only species with variable clutch sizes, maximum body mass, lambda $=0.801$, model $R^{2}=0.286$. Mass, seasonality and NPP estimates are slopes (log 10 transformed except precipitation seasonality). Values (clutch sizes, log 10 transformed) of the categorical variables are for the means of the continuous predictors: a mass of $18.8 \mathrm{~g}$ (back transformed from logarithm), $\log \mathrm{NPP}=11.36\left(\mathrm{~g} \mathrm{C} \mathrm{m}^{-2}, \mathrm{yr}^{-1}, \log 10\right.$ transformed), temperature seasonality $=3.35$ (standard deviation, ${ }^{\circ} C^{*} 100$, log 10 transformed), and precipitation seasonality $=65.9$ (coefficient of variation of monthly values). Values for microhabitats are shown for mainland species. Values for insularity/mainland are shown for terrestrial species. Estimates are presented with their standard errors. $t$ and $p$ values are for differences from zero (i.e., with mass, seasonality and NPP set to zero) for terrestrial and mainland species, from terrestrial species for fossorial and scansorial ones, and from insular species from mainland species. Terrestrial species have similar clutch sizes to both scansorial and fossorial species and there are no significant differences between scansorial and fossorial species $(t=0.677, p=0.498)$. The latitudinal slope for cathemeral species is not shown.

2. Parameter estimates, latitude and activity time model

$\begin{array}{lllll}\text { Factor } & \text { Estimate } & \mathrm{SE} & \mathrm{t} & \mathrm{p} \\ \text { Terrestrial } & 0.572 & 0.114 & 2.074 & 0.038 \\ \text { Fossorial } & 0.526 & 0.116 & 2.260 & 0.024 \\ \text { Scansorial } & 0.553 & 0.115 & 1.902 & 0.057 \\ \text { Mainland } & 0.572 & 0.114 & 2.074 & 0.038 \\ \text { Insular } & 0.472 & 0.115 & 1.180 & 0.238 \\ \text { Latitude (diurnal species) } & 0.003 & 0.001 & 5.595 & <0.0001 \\ \text { Latitude (nocturnal species) } & 0.0005 & 0.0008 & 0.648 & 0.517 \\ \text { Mass } & 0.212 & 0.009 & 23.565 & <0.0001\end{array}$

Only species with variable clutch sizes, maximum body mass, lambda $=0.825$, model $R^{2}=0.256$. Mass (log 10 transformed) and latitude estimates are slopes. Values (clutch sizes, log 10 transformed) of the categorical variables are for the means of the continuous predictors: a mass of $18.8 \mathrm{~g}$ (back transformed from logarithm), latitude (absolute value): $20.92^{\circ}$ (decimal). Values for microhabitats are shown for diurnal mainland species. Values for insularity/mainland are shown for diurnal terrestrial species. Estimates are presented with their standard errors $t$ and $p$ values are for differences from zero (with mass and latitude set to zero) for terrestrial and mainland species, from terrestrial species for fossorial and scansorial ones, and from insular species from mainland species. Terrestrial species have smaller clutches than fossorial - but not scansorial species. There are no significant differences between scansorial and fossorial species $(t=$ $1.251, p=0.211)$. The latitudinal slope for cathemeral species is not shown.

For full results see Appendix 2. 
Table 2. Summary of statistical significance of different models $(\alpha=0.05) .+$ : significant, positively associated with clutch size, -: significant, negatively associated with clutch size, ns: non-significantly associated with clutch size. Fossorial, scansorial, and semi-aquatic species are compared to terrestrial ones. Nocturnal and cathemeral species are compared to diurnal ones (see ANOVA tables in Table 1 for overall significant of multilevel factors). Nocturnal:Iatitude and Cathemeral:latitude are interaction terms and depict whether, and in which direction, the latitudinal slope differs from the slope for diurnal species. VCS: variable clutch size. $n$ (all - deleted): number of species used in the analysis after deletion of species with missing data. $\mathrm{n}$ (deleted): species deleted from the analysis because of missing data. See Table 1 and Appendix 2 for parameter estimates (contrasts and slopes).

A. Models with climatic and environmental predictors (seasonality and NPP)

\begin{tabular}{|c|c|c|c|c|}
\hline Model & $\begin{array}{c}\text { all taxa } \\
\text { average female } \\
\text { size }\end{array}$ & $\begin{array}{c}\text { all taxa } \\
\text { maximum size }\end{array}$ & $\begin{array}{c}\text { VCS taxa } \\
\text { average female } \\
\text { size }\end{array}$ & $\begin{array}{c}\text { VCS taxa } \\
\text { maximum size }\end{array}$ \\
\hline lambda & 0.818 & 0.794 & 0.849 & 0.817 \\
\hline $\mathrm{n}$ & 2617 & 3163 & 1723 & 1995 \\
\hline Mass & + & + & + & + \\
\hline Insularity & - & - & - & - \\
\hline Fossorial & - & - & ns & - \\
\hline Scansorial & - & - & ns & ns \\
\hline Nocturnal & ns & ns & ns & ns \\
\hline Cathemeral & ns & ns & + & + \\
\hline $\begin{array}{l}\text { Seasonality } \\
\text { (precipitation) }\end{array}$ & ns & + & + & + \\
\hline Seasonality & & & & \\
\hline (temperature) & + & + & + & + \\
\hline NPP & + & + & + & + \\
\hline $\mathrm{R}^{2}$ & 0.239 & 0.225 & 0.302 & 0.288 \\
\hline
\end{tabular}

B. Models with latitude and activity times

\begin{tabular}{|lcccc|}
\hline & $\begin{array}{c}\text { all taxa } \\
\text { average female }\end{array}$ & all taxa & VCS taxa & VCS taxa \\
Model & size & maximum size & size & maximum size \\
lambda & 0.818 & 0.794 & 0.854 & 0.825 \\
$\mathrm{n}$ & 2566 & 3238 & 1743 & 2023 \\
\hline Mass & + & + & + & + \\
Insularity & - & - & - & - \\
Fossorial & - & - & ns & ns
\end{tabular}




\begin{tabular}{|lcccc|} 
Nocturnal & $\mathrm{ns}$ & + & $\mathrm{ns}$ & $\mathrm{ns}$ \\
Cathemeral & + & + & $\mathrm{ns}$ & + \\
Latitude & + & + & + & + \\
Nocturnal:latitude & - & - & $\mathrm{ns}$ & $\mathrm{ns}$ \\
Cathemeral:latitude & - & - & $\mathrm{ns}$ & $\mathrm{ns}$ \\
\hline $\mathrm{R}^{2}$ & 0.216 & 0.206 & 0.265 & 0.256 \\
\hline
\end{tabular}


Figure legends and embedded figures

Figure 1. Density plot of mean clutch sizes for the 3916 species analysed, separated between species with fixed (red) and variable (blue) clutch sizes.

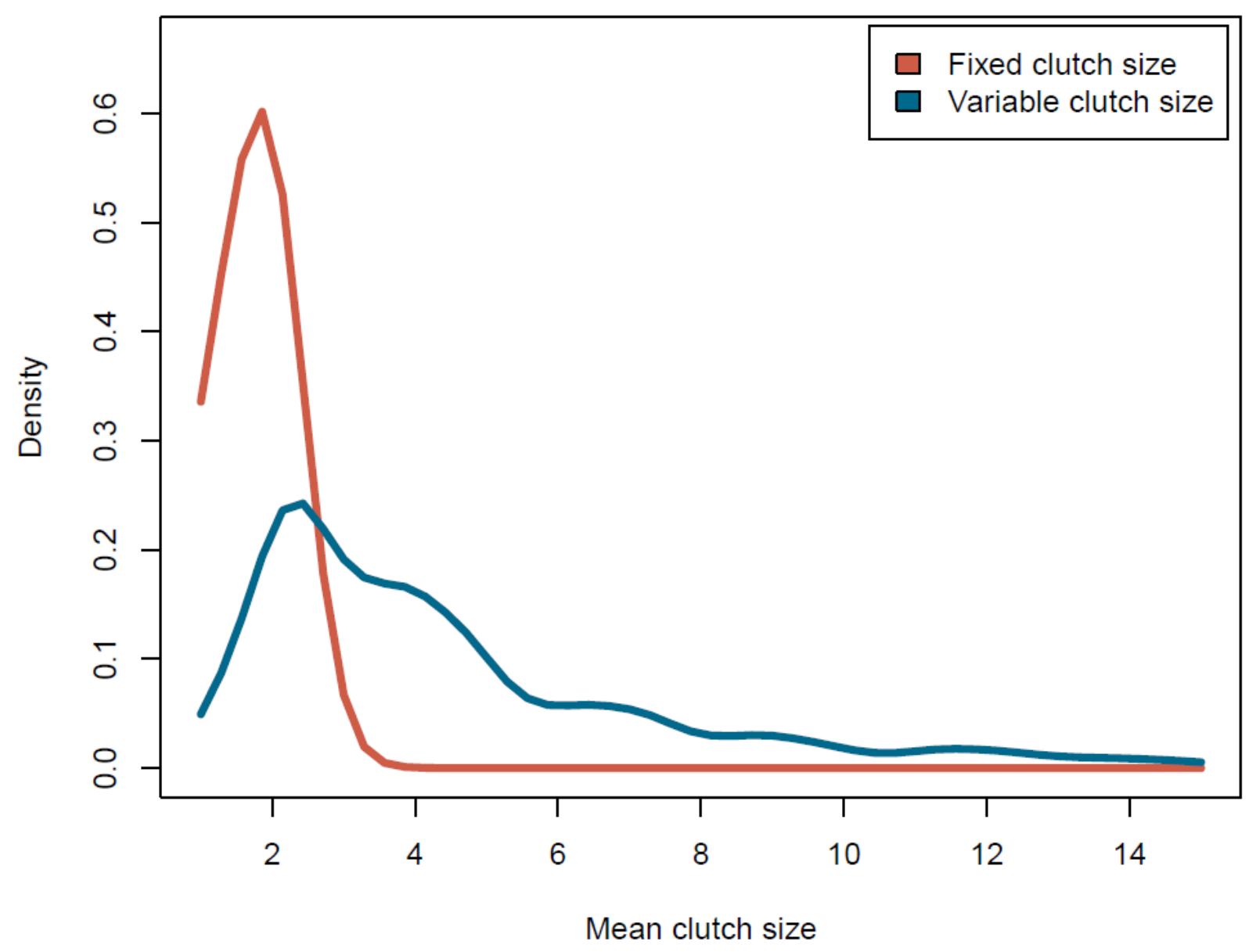

Figure 2. The relationship between clutch size (log10 transformed) and maximum body mass (in grams, $\log 10$ transformed) in the 3916 species in our dataset. The OLS slope is $0.241 \pm 0.005 . R^{2}=0.334$. Taxa with variable clutch sizes shown in blue, those with fixed clutch sizes in red. 


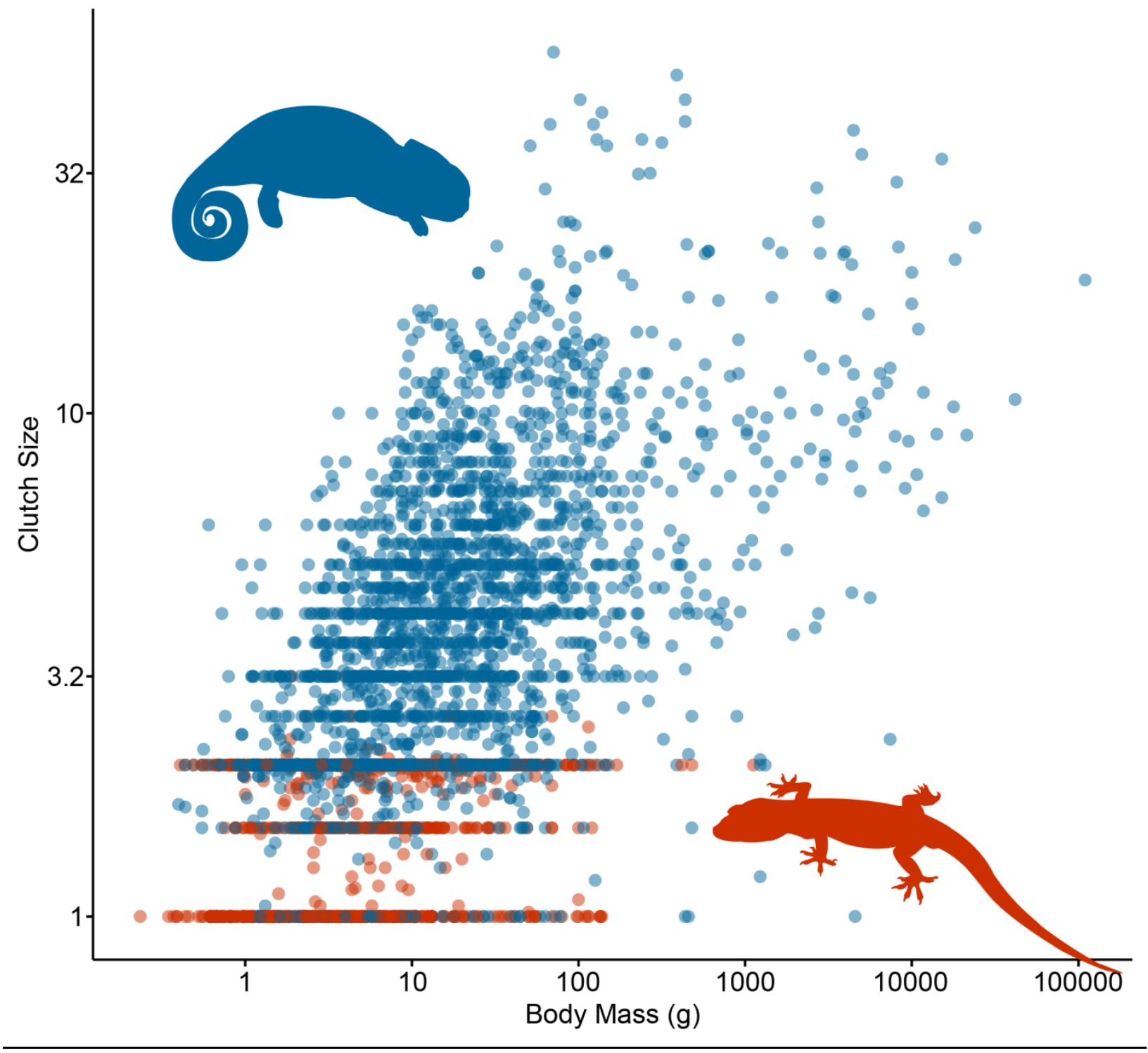

Figure 3. Median log-transformed clutch size in $96^{\star} 96 \mathrm{~km}$ grid cells globally. Top: all lizards; Bottom: only lizards with variable clutch sizes. Note that the colour scale differs between the maps. To the right of each map is a curve showing a generalized additive model of the mapped variable (in black), the $95 \%$ confidence intervals of the mapped variable per $96 \mathrm{~km}$ latitudinal band (shaded dark grey), and the range of values of the mapped variable per $96 \mathrm{~km}$ latitudinal band (shaded light grey). For similar maps where residuals from a phylogenetic clutch-size on body-size analysis are portrayed see Supplementary Figures S1-S2. Equal area Behrmann projection, $96 * 96 \mathrm{~km}$ resolution. 

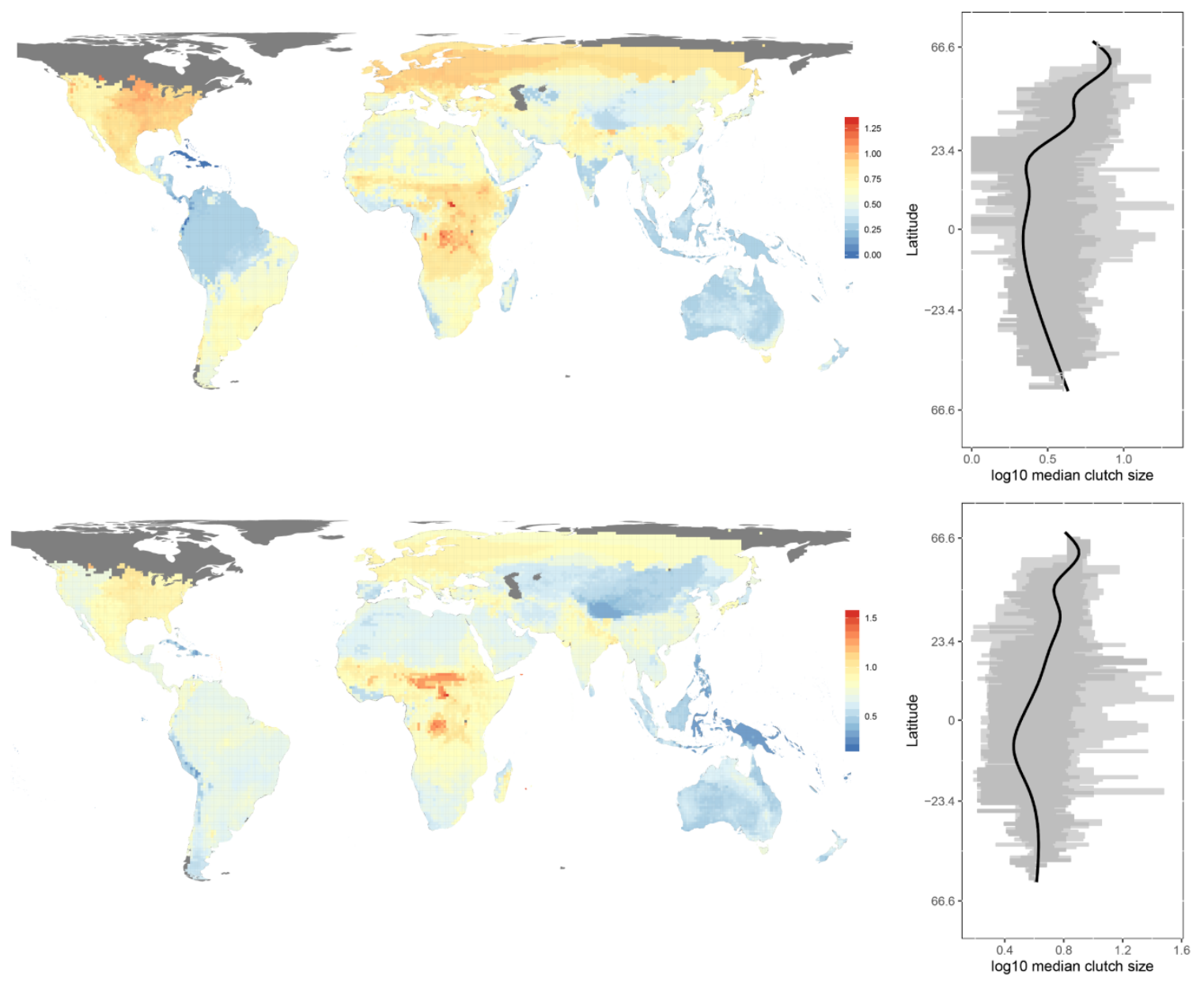

Figure 4. Distribution of lizards with fixed clutch sizes (red). Note that in the northernmost (N. America, N. Eurasia) and southernmost distribution of lizards (S. America; Australia, Tasmania, and New Zealand), and cold regions (e.g., C. Asia, the Caucasus and the Andes), fixed clutched taxa are generally absent. Lizards with variable clutch sizes inhabit all regions (both red and blue) that lizards occur in. White regions have no lizards. Equal area Behrmann projection, $96 * 96 \mathrm{~km}$ resolution. 
29

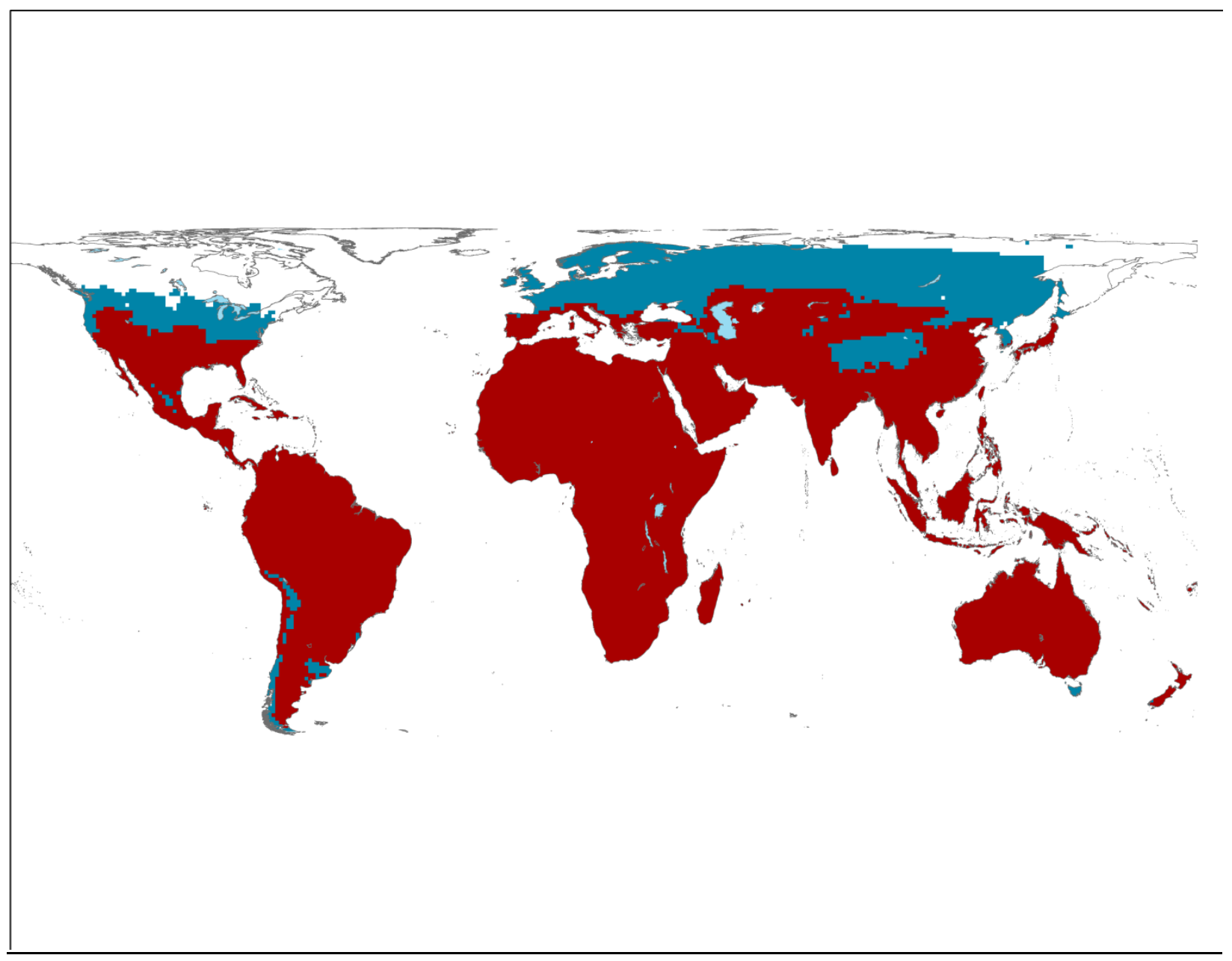




\section{Supplementary Material}

Appendix 1 - The dataset and the metadata used to assemble it

Appendix 2 - Results for all models and sensitivity analyses

Appendix 3 - Supplementary figures

Appendix 4 - Relationships between the activity season of lizards and latitude, temperature seasonality, and precipitation seasonality of their ranges

Appendix 5-Comparisons of clutch sizes of saxicolous and arboreal lizards 